\title{
ANÁLISE MICROSCÓPICA DO EFEITO DA RADIOTERAPIA FRACIONADA EM GLÂNDULA SUBMANDIBULAR DE RATO*
}

\author{
Fabiana Vieira Vier-Pelisser ${ }^{1}$, José Miguel Amenábar ${ }^{1}$, Karen Cherubini ${ }^{2}$, Maria Antonia \\ Zancanaro de Figueiredo ${ }^{2}$, Liliane Soares Yurgel $^{3}$
}

Resumo OBJETIVO: $O$ estudo teve por objetivo avaliar, quantitativamente, as alterações histológicas induzidas pela radioterapia sobre o parênquima e o estroma da glândula submandibular. MATERIAIS E MÉTODOS: A amostra foi constituída por 30 ratos Wistar, distribuídos em dois grupos: teste e controle. Os 15 animais do grupo-teste foram submetidos a radioterapia da região de cabeça e pescoço, na modalidade fracionada rotacional por cobalto-60, na dose de $60 \mathrm{~Gy}$, realizada em frações de 2 Gy diários, por seis semanas. Decorridas 60 horas da conclusão da radioterapia, as glândulas submandibulares dos animais de ambos os grupos foram excisadas, processadas pela técnica da parafina, coradas com hematoxilina e eosina e analisadas à microscopia óptica. $\mathrm{O}$ volume proporcional médio correspondente ao parênquima e ao estroma glandulares foi obtido pelo método estereológico de contagem manual de pontos. RESULTADOS: 0 volume proporcional de ácinos no grupo irradiado $(60,67 \% \pm 6,43)$ foi significativamente menor que no grupo-controle $(67,42 \% \pm$ $10,90)(p=0,048)$, entretanto, não houve diferença estatisticamente significativa entre os grupos para as variáveis parênquima, ductos e estroma (teste $t$ de Student, $p>0,05$ ). CONCLUSÃO: 0 esquema radioterápico empregado provocou atrofia acinar da glândula submandibular, sem, no entanto, ocorrer alteração quantitativa total do estroma ou do parênquima.

Unitermos: Ratos; Glândula submandibular; Radioterapia; Microscopia.

Abstract Microscopic analysis of the effect of fractionated radiation therapy on submandibular gland of rats.

OBJECTIVE: The aim of this study was to quantitatively evaluate the histological changes produced by radiation therapy both on the stroma and the parenchyma of submandibular gland in rats. MATERIALS AND METHODS: The sample size consisted of 30 Wistar rats, divided in two groups: test and control. The 15 animals of the test group were irradiated daily on the head and neck region with a dose of 2 Gy for six weeks using a rotational fractionated modality of ${ }^{60} \mathrm{Co}$-gamma rays. At the end of the experimental period the animals had received a total dose of $60 \mathrm{~Gy}$. Sixty hours after the last radiation therapy session the submandibular glands of the animals from both groups were excised, processed using paraffin technique, stained with hematoxiline-eosin and analyzed by optical microscopy. RESULTS: The mean proportional volume of the glandular parenchyma and stroma was obtained using a stereological method of manual point counting. The proportional volume of the acini on the irradiated group $(60.67 \% \pm 6.43)$ was significantly lower than the control group $(67.42 \% \pm 10.90)(p=0.048)$, however there was no statistical difference between the groups for parenchyma, ducts and stroma (Student $t$ test, $p>0.05$ ). CONCLUSION: The radiation therapy produced acinar atrophy in submandibular glands. No total quantitative changes in the stroma or in the parenchyma were observed.

Key words: Rats; Salivary gland; Radiotherapy; Microscopy.

\section{INTRODUÇÃO}

A radioterapia do câncer da região de cabeça e pescoço determina dano ao pa-

* Trabalho realizado no Programa de Doutorado em Estomatologia Clínica da Pontifícia Universidade Católica do Rio Grande do Sul (PUC/RS), Porto Alegre, RS.

1. Alunos do Programa de Doutorado em Estomatologia Clínica da PUC/RS.

2. Doutoras em Estomatologia Clínica, Professoras do Programa de Doutorado em Estomatologia Clínica da PUC/RS.

3. Doutora em Estomatologia Clínica, Coordenadora e Professora do Programa de Doutorado em Estomatologia Clínica da PUC/RS.

Endereço para correspondência: Profa. Dra. Karen Cherubini. Hospital São Lucas da PUC/RS - Serviço de Estomatologia. Avenida Ipiranga, 6690, sala 231. Porto Alegre, RS, 90610000 E-mail: kebini.ez@terra.com.br

Recebido para publicação em 4/3/2005. Aceito, após revisão, em 18/3/2005. rênquima das glândulas salivares e tem como sequiela mais frequiente a xerostomia $^{(\mathbf{1})}$. Decorridas uma ou duas semanas do início do tratamento, podem ocorrer alterações nas glândulas salivares, caracterizadas pela diminuição ou mesmo ausência completa de secreção. A perda da secreção pode constituir uma seqüela permanente da radiação, ou seguir-se de recuperação gradual do fluxo salivar, o que ocorre, em geral, após alguns meses ${ }^{(2)}$.

Além do desconforto de uma boca que prescinde de lubrificação apropriada, o decréscimo do fluxo salivar prejudica significativamente a ação bactericida e de autolimpeza da saliva. Sem intervenção, aumento de cáries, predominantemente cervicais, pode ocorrer ${ }^{(3)}$. O grau do dano induzido pela radiação nas glândulas salivares depende da dose aplicada e de seu fracionamento, bem como da localização do tecido glandular no campo irradiado ${ }^{(4)}$.

English $^{(5)}$ investigou as alterações histológicas induzidas pelos raios X em glândula submandibular de ratos. Os animais foram submetidos a doses de 10 e 15 Gy e sacrificados aos 16 dias e 21 dias após o término da irradiação. O exame histológico com coloração pela técnica hematoxilina e eosina (HE) exibiu alterações no tamanho, na forma e na pigmentação do núcleo das células acinares. 
Cherry e Glucksmann ${ }^{(6)}$ irradiaram com raios $\mathrm{X}$ a região do pescoço de 62 ratos, em sessões de $8,5 \mathrm{~Gy}$, variando a dose total de 25,5 a 76,5 Gy. Os animais foram sacrificados em intervalos que variaram de uma hora a um ano após concluída a irradiação, e a glândula submandibular foi submetida à avaliação histológica. Nas glândulas expostas a doses de 30 Gy ou mais, inicialmente foram observadas alterações degenerativas, seguidas por mudanças regenerativas. O modelo de reparo foi considerado anormal, uma vez que resultou na formação de adenomas. Os ácinos foram as estruturas mais afetadas pela radiação, sendo que a massa acinar apresentou redução progressiva que foi acompanhada de aumento da quantidade de tecido conjuntivo intersticial.

Frank et al. ${ }^{(7)}$ avaliaram, à microscopia óptica, 21 glândulas salivares provenientes de ressecções radicais de carcinomas da cavidade bucal, faringe e laringe de pacientes expostos à teleterapia por cobalto-60 (30 a 60 Gy de cada lado). Houve redução do tamanho dos ácinos das glândulas salivares, assim como infiltração por plasmócitos, edema, fibrose e espessamento do tecido conjuntivo interlobular, características evidenciadas entre 45 dias e 90 dias após a irradiação. No período entre 105 dias e 120 dias, importante fibrose intersticial e interlobular estava presente.

Elzay et al.$^{(8)}$ irradiaram 66 ratos albinos com cobalto-60, nas doses de 24,48 e $72 \mathrm{~Gy}$. Os animais foram expostos a $6 \mathrm{~Gy}$ diários, durante um período de duas a seis semanas. Inflamação discreta do estroma interlobular, com pequena a moderada atrofia e pleomorfismo dos ácinos foram observados na glândula submandibular. Discreta vacuolação citoplasmática foi percebida 45 dias após a dose de 24 Gy, fato verificado também aos sete dias pósirradiação de 48 Gy. Ainda, os ácinos submetidos a 48 Gy exibiram pleomorfismo e atrofia 41 dias após o término do tratamento radioterápico. Por volta do $45^{\circ}$ dia, foram verificados edema marcante dos ácinos, fragmentação do septo acinar e proeminência nuclear. No $35^{\circ}$ dia pós-irradiação, a glândula submandibular dos animais que receberam 72 Gy exibiu discreta vacuolação citoplasmática dos ácinos, bem como atrofia e pleomorfismo marcantes.
Sinn et al.${ }^{(9)}$ investigaram, por meio de microscopia óptica, o efeito imediato e tardio de doses fracionadas de cobalto-60 na glândula submandibular de ratos. Os autores submeteram 18 ratos a dose total de 60 Gy, divididos em cinco sessões semanais durante seis semanas. Os animais foram sacrificados nos períodos de dois dias, seis semanas e 12 semanas após o término da radioterapia. Seis animais não foram irradiados, servindo como controle. Diminuição significativa da proporção de células serosas foi observada, enquanto nenhuma alteração ocorreu na proporção de ácinos mucosos. O aumento da vacuolação citoplasmática foi constantemente observado nos ácinos mucosos das glândulas dos animais sacrificados imediatamente após a radioterapia. Em 20\% dos animais foi observada fibrose sem a presença de alterações vasculares, edema ou inflamação.

Savage et al. ${ }^{(10)}$ expuseram 24 ratos à radiação $\mathrm{X}$ em doses cumulativas fracionadas de 5, 7,5 e 10 Gy, distribuídos em seis grupos de quatro indivíduos cada, sendo que, em cada grupo, um animal foi empregado como controle e os três restantes, expostos às diferentes doses de radiação. As glândulas submandibulares foram processadas e coradas com HE. O tecido glandular dos animais sacrificados três dias após o término da radioterapia mostrou atrofia acinar, quando comparado ao grupo-controle, principalmente no grupo que recebeu a dose de $10 \mathrm{~Gy}$. Áreas isoladas exibiram danos mais graves como vacuolação, apoptose e destruição total da célula. Estas alterações foram mais acentuadas com $\mathrm{o}$ aumento progressivo da dose de radiação administrada. Poucos ductos intercalares foram observados no grupo-controle, ao passo que, nas glândulas irradiadas, tais ductos tornaram-se uma característica marcante. Os animais sacrificados aos 14 dias pós-irradiação, independentemente da dose, mostraram aspecto morfológico glandular semelhante ao do grupo não-irradiado.

Savage et al. ${ }^{(11)}$ estudaram, na mesma amostra, às microscopias óptica e eletrônica de transmissão, a microvasculatura de glândulas submandibulares expostas à radiação. À microscopia óptica não foram observadas alterações vasculares aos três dias, mas, aos 14 dias, os vasos tornaramse proeminentes e ingurgitados. As mudan- ças ultra-estruturais aos três dias consistiram em edema endotelial marcante com um pequeno número de células contendo vacúolos citoplasmáticos grandes e muitas cavéolas delimitando as membranas celulares do endotélio. O parênquima afetado restringiu-se a áreas aparentemente suportadas por esses vasos sanguíneos. Aos 14 dias, a maioria dos vasos exibia características normais.

Stephens et al. ${ }^{(\mathbf{1 2})}$ avaliaram os aspectos morfológicos dos danos agudo e crônico induzidos pela radiação em ácinos serosos e mucosos de glândulas submandibulares de 18 macacos expostos a doses únicas de 2,5 a 15 Gy. Vinte e quatro horas após a exposição às doses de 10 a 15 Gy, foi observada destruição generalizada de ácinos serosos inteiros, enquanto as células mucosas foram afetadas apenas de forma isolada. Aumento de células serosas vacuoladas e, conseqüentemente, necróticas, foi observado com o passar do tempo e com o aumento da dose. A avaliação nos intervalos de 16 a 22 semanas e 40 semanas pós-radioterapia revelou atrofia conseqüente à perda dos ácinos serosos em glândulas tratadas com 7,5 e 10 Gy. Embora tanto o número de ácinos serosos quanto o de mucosos tivessem diminuído em glândulas tratadas com 12,5 e $15 \mathrm{~Gy}$, a atrofia observada foi devida principalmente à perda dos ácinos serosos. A diminuição do tecido acinar foi acompanhada de aumento de colágeno inter e intralobular.

Segundo Shafer $e t$ al..$^{(2)}$, a glândula salivar irradiada apresenta dano evidente nas células acinares, representado, principalmente, por diminuição do número de grânulos secretores, congestão, edema e infiltrado inflamatório no tecido conjuntivo intersticial. Porém, os ductos das glândulas não mostram alterações dignas de nota.

Ahlner et al.$^{(13)}$ notaram que a radiação X, em dose única de $15 \mathrm{~Gy}$, causou dano tecidual em glândulas submandibulares de coelhos, que persistiu dos quatro aos dez meses pós-tratamento. Os ácinos seromucosos estavam parcialmente atrofiados, com alteração da arquitetura e reduzido tamanho granular, enquanto os ácinos serosos mostravam redução pronunciada de grânulos aos quatro meses e notável regeneração adenomatosa aos dez meses. Já os ductos estriados não exibiram alterações 
significativas no período analisado. As alterações arteriolares variaram de leves a moderadas, não havendo dano capilar.

Price et al. ${ }^{(14)}$ avaliaram as alterações histológicas induzidas pela irradiação com cobalto-60 em glândulas submandibulares de macacos. Foram empregados esquemas fracionados convencionais: 20 sessões, em quatro semanas, totalizando $50 \mathrm{~Gy} ; 25$ sessões, em cinco semanas, totalizando 55 Gy; e radioterapia acelerada hiperfracionada contínua (RAHC): 54 Gy em 36 sessões durante 12 dias. Os resultados revelaram atrofia e fibrose glandular graves, sendo que a magnitude da atrofia, no período de 16 semanas após o término da radioterapia, foi similar entre os esquemas radioterápicos empregados.

Navarro et al. ${ }^{(\mathbf{1 5})}$ expuseram as glândulas submandibulares de 30 ratos a 1,8 Gy de radiação $X$. Os animais foram sacrificados nos períodos de 24, 48, 72 horas e 7, 14 e 21 dias após a irradiação, e suas glândulas submandibulares analisadas à microscopia óptica. Decorridas 24 horas, os ácinos e ductos estriados exibiam núcleos aumentados e hipercromáticos, cariorrexe e pleomorfismo, além de inversão de polaridade nuclear. Visualizaram-se, ainda, granulações, vacuolações citoplasmáticas e algumas figuras de mitose. Nos dois períodos subseqüentes, os mesmos fenômenos foram observados, porém em grau mais acentuado e acrescidos de vacuolação citoplasmática das células acinares, notando-se, eventualmente, espaços vasculares aumentados contendo grande quantidade de hemácias. Nos períodos de 7, 14 e 21 dias após a irradiação, as células acinares mostraram discreto pleomorfismo nuclear e nucléolos evidentes. Porém, a partir do sétimo dia, a intensidade dessas alterações foi menor, se comparada àquela percebida nos primeiros períodos experimentais.

Friedrich et al. ${ }^{(\mathbf{1 6})}$ irradiaram, com raios $\mathrm{X}$, a região de cabeça e pescoço de 60 ratos, em doses totais de 20, 40 e 60 Gy, fracionadas em sessões de 2 Gy. Nos períodos de seis meses e um ano após a irradiação, os animais foram sacrificados e suas glândulas submandibulares foram submetidas a exames histológico e imuno-histoquímico. Houve diferença estatisticamente significativa no padrão e na intensidade de coloração entre as glândulas irradiadas e controles. Os autores verificaram que a radiação altera a quantidade e a composição da matriz extracelular de glândulas salivares, sendo que a variação da quantidade é dose-dependente. Além disso, o aumento da dose de radiação está associado a maior perda acinar.

Coppes et al. ${ }^{(17)}$ investigaram o efeito da radiação na fisiologia das glândulas parótida e submandibular de ratos. Os animais foram expostos à radiação em dose única, em dose fracionada convencional e em dose fracionada acelerada. Amostras de saliva das glândulas parótida e submandibular/sublingual foram coletadas antes e até 240 dias após a irradiação. Fluxo salivar, fase "lag" e secreção de amilase foram usados como critérios de avaliação da função glandular. Nenhuma diferença foi observada entre as glândulas ou entre os diferentes esquemas de irradiação, nas avaliações realizadas até 120 dias após o tratamento. No entanto, os autores observaram que, após este período, as variáveis fluxo salivar e fase "lag" mostraram-se superiores na glândula parótida, em relação à submandibular, quando do emprego da radiação fracionada. Os autores concluíram que a radiossensibilidade em períodos superiores a 120 dias pós-irradiação é maior na glândula submandibular do que na parótida, quando se empregam esquemas radioterápicos fracionados.

Radfar e Sirois ${ }^{(\mathbf{1 8})}$ submeteram três porcos-da-Índia à irradiação diária fracionada totalizando $70 \mathrm{~Gy}$, sacrificando-os 30 dias após a conclusão da radioterapia. Nenhuma alteração patológica foi observada nas glândulas parótidas e submandibulares dos dois animais do grupo-controle. Entretanto, nas irradiadas, foi verificada perda significativa de parênquima, com intensa atrofia acinar e fibrose intersticial, núcleos aumentados nas células acinares remanescentes, assim como dilatação e proliferação ductais. Além disso, durante o mesmo período, o fluxo salivar estimulado foi reduzido em $81 \%$ nos animais irradiados, quando comparado com o fluxo pré-irradiação, e aumentado em $30 \%$ no grupo-controle.

Nagler ${ }^{(19)}$ avaliou os efeitos precoces e tardios da radiação em glândulas salivares de roedores, e verificou disfunção e perda tecidual das glândulas salivares até um ano pós-tratamento radioterápico. O prejuízo induzido pela radiação foi tardio tanto na parótida quanto na submandibular, embora mais evidente na primeira. Íons metálicos de transição associados aos grânulos secretores, com alto potencial de oxirredução, como o ferro e o cobre, causam a morte tardia das células serosas e conseqüente radiossensibilidade específica da parótida.

Pacientes submetidos à radioterapia da região de cabeça e pescoço exibem, durante e após o tratamento, diminuição da secreção salivar $^{(20)}$, visto que as glândulas salivares estão incluídas nos portais de irradiação. $\mathrm{O}$ conhecimento das alterações histológicas que ocorrem no parênquima e no estroma glandulares de pacientes irradiados é importante para o manejo do paciente xerostômico. Além disso, apesar das evidências de que a radioterapia provoca dano no tecido glandular, a maioria das pesquisas ocupa-se em descrever esse dano sem quantificá-lo. Assim, o presente estudo investigou alterações no volume proporcional médio do estroma e do parênquima de glândula submandibular de rato, induzidas pela radioterapia fracionada rotacional por cobalto-60.

\section{MATERIAIS E MÉTODOS}

O presente estudo teve seu protocolo aprovado pela Comissão Científica e de Ética da Faculdade de Odontologia da Pontifícia Universidade Católica do Rio Grande do Sul (PUC/RS).

A amostra foi constituída por 30 ratos albinos machos, com 80 dias de idade, da espécie Rattus norvegicus, linhagem Wistar, pesando entre 140 e $300 \mathrm{~g}$, procedentes do Biotério da Universidade Federal do Rio Grande do Sul (UFRGS). Os animais tiveram à sua disposição, durante todo o período experimental, ração tipo Labina e água ad libitum e foram distribuídos aleatoriamente em dois grupos: teste e controle. Os 15 animais do grupo-teste receberam a dose radioterápica de 60 Gy, sendo sacrificados ao final da radioterapia. Os 15 animais do grupo-controle não foram irradiados, sendo mantidos nas mesmas condições ambientais do grupo-teste.

Os animais do grupo-teste foram irradiados utilizando-se unidade de teleterapia rotacional por cobalto-60 (Philips, modelo XK 5101), com energia de 1,25 MeV. 
A dose total empregada foi de $60 \mathrm{~Gy}$, dividida em 30 frações de 2 Gy, aplicados durante 15 minutos de radioterapia diária. As doses foram administradas de segunda a sexta-feira, num período de seis semanas ${ }^{(21)}$. A distância entre o ponto de emissão do feixe de radiação e a superfície cutânea dos animais foi de $60 \mathrm{~cm}$. A região de cabeça e pescoço dos animais estava no interior do campo de emissão da radiação, que media $20 \times 20 \mathrm{~cm}$, e os animais foram imobilizados durante a sessão por meio de dispositivos plásticos (Figura 1).

Os animais foram anestesiados com Thionembutal (tiopental sódico) e Ketamin-S + (cloridrato de $\mathrm{S}+$ cetamina, 22 $\mathrm{mg} / \mathrm{kg}$ ) e suas glândulas submandibulares foram dissecadas e fixadas em formaldeído a 10\%, 60 horas após a conclusão do esquema radioterápico. A glândula direita de cada animal foi seccionada em três porções de tamanhos similares, mesial, média e distal, para inclusão em parafina e obtenção de cortes histológicos corados com HE. Cada lâmina foi composta por três cortes histológicos. A análise microscópica foi realizada em microscópio Olympus AX 70, com objetiva de dez aumentos, usando-se o programa Image Pro-Plus versão 4.0.

Foram selecionados três campos por lâmina, isto é, um campo para cada corte. O campo escolhido em cada corte foi sempre aquele disposto mais superiormente e à esquerda na lâmina. As imagens microscópicas foram capturadas e, sobre elas, foram dispostos 320 pontos eqüidistantes. O número de pontos foi previamente calculado, mediante intervalo de confiança de 95\%. As sobreposições desses pontos a ácinos, ductos e estroma foram especificadas e quantificadas (Figura 2).

A frequiência de cada variável foi calculada nos três cortes de cada glândula, por um único observador, previamente calibrado e cegado quanto ao grupo a que pertencia a lâmina avaliada. Após, a média da porcentagem das três avaliações foi obtida para cada espécime. Assim, as proporções correspondentes ao parênquima, discriminado em ácinos e ductos, e ao estroma glandular foram obtidas. As variáveis parênquima (ácinos e ductos) e estroma foram comparadas entre os grupos, por meio do teste $t$ de Student, considerando-se o nível de significância de $5 \%$.

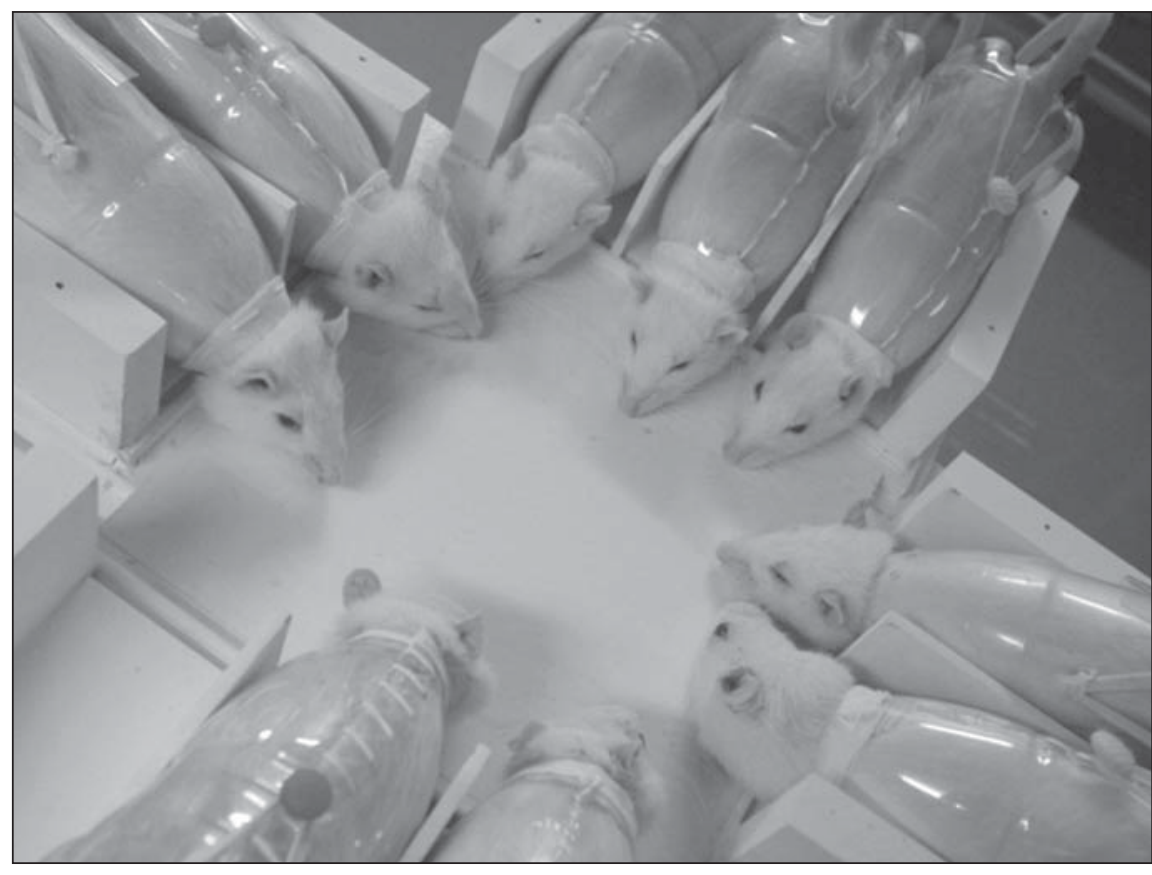

Figura 1. Imobilização dos animais em dispositivos plásticos, acoplados a um suporte de madeira, de modo que apenas a região de cabeça e pescoço estivesse no campo de radiação.

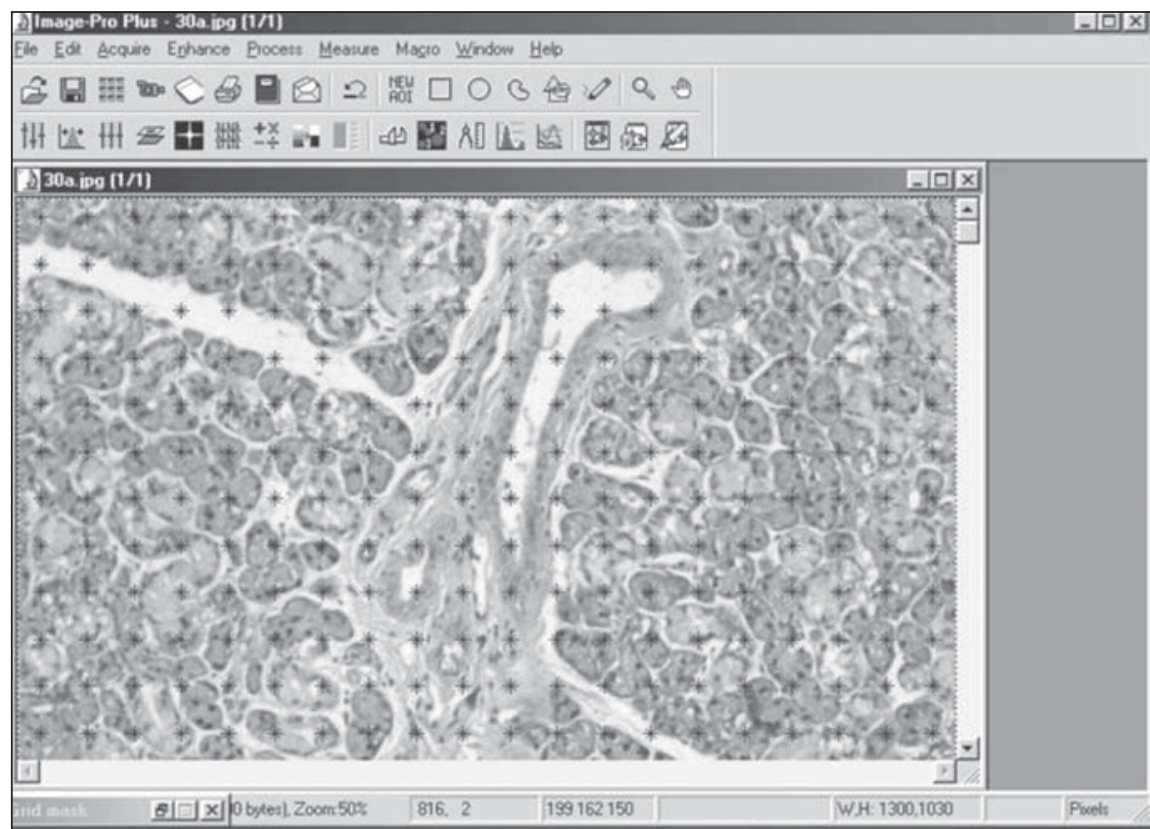

Figura 2. Imagem da glândula submandibular à qual foi sobreposta a grade de 320 pontos, para mensuração da coincidência entre os pontos e as estruturas histológicas (programa Image Pro Plus).

\section{RESULTADOS}

Os resultados da análise quantitativa dos constituintes teciduais da glândula submandibular estão apresentados na Tabela 1 e na Figura 3. O volume proporcional médio de ácinos para os grupos teste e controle foi, respectivamente, $60,67 \%$ e $67,42 \%$. Uma vez aplicado o tratamento estatístico, verificou-se diferença significativa entre esses valores, isto é, o volume proporcional de ácinos no grupo irradiado (grupo-teste) foi significativamente menor que no grupo-controle (teste $t$ de Student, 


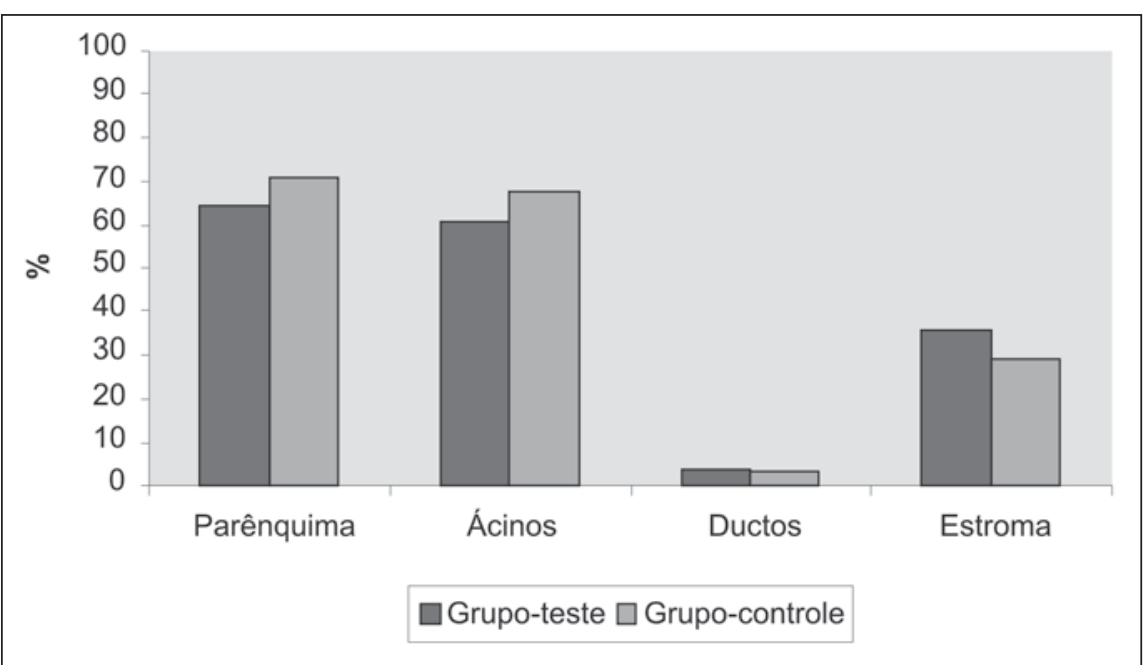

Figura 3. Volume proporcional médio dos componentes histológicos da glândula submandibular de rato dos grupos irradiado (teste) e controle.

Tabela 1 Volume proporcional médio dos componentes histológicos da glândula submandibular de rato dos grupos irradiado (teste) e controle.

\begin{tabular}{|l|c|c|c|}
\hline & $\begin{array}{c}\text { Grupo-teste } \\
\text { Média (\%) } \pm \mathrm{DP} *\end{array}$ & $\begin{array}{c}\text { Grupo-controle } \\
\text { Média (\%) } \pm \mathrm{DP} *\end{array}$ & $p^{\dagger}$ \\
\hline Parênquima & $64,25 \pm 6,43$ & $70,65 \pm 10,91$ & 0,061 \\
Ácinos & $60,67 \pm 6,43$ & $67,42 \pm 10,90$ & $\mathbf{0 , 0 4 8}$ \\
Ductos & $3,58 \pm 1,87$ & $3,22 \pm 1,43$ & 0,558 \\
Estroma & $35,75 \pm 6,53$ & $29,35 \pm 10,91$ & 0,061 \\
\hline
\end{tabular}

* DP, desvio-padrão. ${ }^{\dagger}$ Teste $t$ de Student, diferença significativa se $p=0,05$.

$p=0,048)$. Por outro lado, não houve diferença estatisticamente significativa entre os grupos para os componentes parênquima, ductos e estroma (teste $t$ de Student, $p>$ $0,05)$. No entanto, embora a diferença não tenha sido significativa, os animais submetidos à radioterapia exibiram menor volume proporcional médio de parênquima e ductos e maior de estroma do que o grupo-controle.

\section{DISCUSSÃO}

Algumas pesquisas relatam que a irradiação da glândula submandibular provoca atrofia acinar, que se caracteriza por redução do tamanho dos ácinos ou perda do parênquima, acompanhada de fibrose ou aumento da quantidade de tecido conjun-

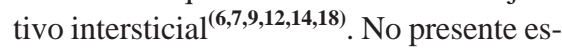
tudo houve diminuição estatisticamente significativa ( $p=0,048)$ do volume proporcional médio da massa acinar no grupo de animais submetidos ao regime radiote- rápico, quando comparado ao grupo-controle. Todavia, o volume do estroma glandular não mostrou diferença significativa entre os grupos, embora a média desta variável, no grupo-teste, tivesse sido superior à do grupo-controle. Considerando-se que o valor de $p$ foi de 0,06 , isto é, próximo de 0,05 , e que a amostra empregada correspondeu a 15 animais em cada grupo, não fica descartada a possibilidade de que o tamanho da amostra tenha contribuído para tal resultado. Talvez, um $n$ maior tivesse revelado diferença estatisticamente significativa também para esta variável.

Radfar e Sirois ${ }^{(\mathbf{1 8})}$ e Nagler ${ }^{(\mathbf{1 9})}$ verificaram redução do peso das glândulas parótida e submandibular expostas à radiação. É provável que tal redução esteja associada à perda de volume acinar, pois a maioria das pesquisas ${ }^{(\mathbf{1}, 5,8,10,13,16)}$ relata o efeito da radiação sobre o parênquima glandular, sem mencionar alterações no estroma, o que estaria em concordância com os nossos achados.
Sinn et al. ${ }^{(9)}$, após aplicarem o mesmo esquema radioterápico do presente estudo, notaram diminuição significativa na proporção de células serosas, sem alteração semelhante no componente mucoso. As células serosas parecem ser mais radiossensíveis que as mucosas devido ao conteúdo de seus grânulos secretores, ricos em metais pesados como zinco, manganês e ferro. Membranas que contêm organelas ricas em metais capazes de formar sistemas de oxirredução mostram sensibilidade aumentada à radiação devido à peroxidação lipídica de metais por ela induzida ${ }^{(22)}$. Na presente pesquisa, não foi realizada a quantificação discriminatória dos diferentes tipos de ácinos. Entretanto, esse procedimento poderia ter fornecido resultados ainda mais significativos para a variável em questão e deve ser considerado em novos estudos.

Stephens et al..$^{(\mathbf{1 2})}$ perceberam atrofia acinar associada a aumento de colágeno inter e intralobular, em espécimes avaliados tardiamente, ou seja, no período de 16 a 40 semanas após a conclusão da radioterapia. Segundo Mathes e Alexander ${ }^{(23)}$, o aumento da fibrose e a diminuição da vascularização constituem efeitos tardios da radiação. No presente estudo, não foi verificada diferença significativa do volume de estroma entre os grupos irradiado e controle. Como justificativas para tal achado, podem-se citar o tempo decorrido da radioterapia na avaliação dos espécimes, que foi de 60 horas pós-tratamento, bem como a análise quantitativa do estroma sem discriminar seus constituintes. Na quantificação total do estroma, a diminuição da vascularização pode ter sido compensada pelo aumento da fibrose. Assim, se a avaliação dos espécimes tivesse sido realizada a longo prazo, discriminando os componentes estromais, é possível que alterações significativas dessa variável tivessem sido observadas.

O mecanismo do dano causado pela radiação no tecido glandular não é inteiramente conhecido. Efeitos citotóxicos diretos nas células acinares, bem como efeitos secundários conseqüentes à isquemia, obstrução de ductos e uma variedade de processos fisiológicos que afetariam a desgranulação da secreção são mencionados. Sinn et al..$^{(\mathbf{9})}$ e Savage et al..$^{(11)}$ demonstraram alterações nos vasos sanguíneos de 
glândulas submandibulares de ratos irradiados, reforçando a premissa de que alterações na microvascularização deste tecido poderiam ser um dos fatores responsáveis pelo dano tecidual. A hipóxia, que pode advir de alterações vasculares, prejudica a respiração oxidativa aeróbica celular, com conseqüente dano à célula. De acordo com a intensidade do estado hipóxico, as células podem adaptar-se, sofrer lesão ou morrer ${ }^{(\mathbf{2 4})}$. Já Stephens et al. ${ }^{(\mathbf{1 2})}$ acreditam que o dano às células acinares, como a atrofia, resulta de efeito direto da radiação sobre este tecido.

A dose de radiação preconizada para o tratamento do câncer da região de cabeça e pescoço varia de 40 a $70 \mathrm{~Gy}$, fracionada em doses diárias de 2 Gy, por um período de quatro a sete semanas ${ }^{(25)}$. Este protocolo foi seguido na presente pesquisa, para que os resultados pudessem ser extrapolados para a clínica. Autores como Sinn et al. ${ }^{\left({ }^{(9)} \text {, }\right.}$ Friedrich et al. ${ }^{(\mathbf{1 6})}$ e Radfar e Sirois ${ }^{(\mathbf{1 8 )}} \mathrm{em}$ pregaram o mesmo esquema terapêutico, apesar de terem utilizado cobalto-60, raios $\mathrm{X}$ e acelerador linear, respectivamente, como fontes de radiação. A modalidade terapêutica empregada parece ser fator importante a ser considerado no grau do dano tecidual causado pela radiação, uma vez que os efeitos da megavoltagem, aplicada em esquemas fracionados no tecido glandular, parecem ser menores, quando comparados com aqueles resultantes da ortovoltagem fracionada ${ }^{(\mathbf{8})}$.

Apesar de a parótida ser a maior das glândulas salivares e, por conseguinte, responsável pela maior produção de saliva ${ }^{(26)}$, no presente estudo empregou-se a submandibular como protótipo, devido à constituição mista desta glândula, que proporciona a avaliação de ambas as estruturas, serosas e mucosas.

Os resultados do presente estudo sugerem a realização de novas pesquisas, conduzidas em diferentes intervalos após a conclusão da radioterapia, no intuito de verificar-se o dano tardio ao parênquima e ao estroma das glândulas submandibulares. Seria interessante, também, a quantificação discriminatória dos componentes do estroma glandular, em vasos sanguíneos e fibras colágenas, a fim de avaliar o efeito da radiação sobre a vascularização da glândula e índice de fibrose.

\section{CONCLUSÃO}

A partir dos resultados obtidos no presente estudo, foi possível concluir que o esquema radioterápico de 60 Gy, distribuído em doses fracionadas de 2 Gy, de segundas às sextas-feiras, por seis semanas, provoca atrofia acinar, observada 60 horas após a conclusão do tratamento. A atrofia é evidenciada pela diminuição da proporção de ácinos, sem ocorrer, entretanto, alteração da proporção total do estroma e do parênquima glandular.

\section{REFERÊNCIAS}

1. Liu R, Seikaly H, Jha N. Anatomic study of submandibular gland transfer in an attempt to prevent postradiation xerostomia. J Otolaryngol 2002;31: 76-79.

2. Shafer WG, Hine MK, Levy BM. Lesões físicas e químicas da cavidade bucal. In: Shafer WG, Hine MK, Levy BM, editors. Tratado de patologia bucal. 4 ed. Rio de Janeiro, RJ: Guanabara Koogan, 1987;486-548.

3. Neville BW, Damm D, Allen CM, Bouquot JE. Injúrias físicas e químicas. In: Neville BW, Damm $\mathrm{DD}$, Allen CM, Bouquot JE, editors. Patologia oral e maxilofacial. Rio de Janeiro, RJ: Guanabara Koogan, 1998;205-229.

4. Bartel-Friedrich S, Friedrich RE, Lautenschläger C, Holzhausen HJ, Moll R. Dose-response relationships on the expression profile of cytokeratins and vimentin in rat submandibular glands following fractionated irradiation. Anticancer Res 2000;20: 4917-4926.

5. English JA. Morphologic effects of irradiation on the salivary glands of rats. J Dent Res 1955;34:411.

6. Cherry CP, Glucksmann A. Injury and repair following irradiation of salivary glands in male rats. Br J Radiol 1959;32:596-608.

7. Frank RM, Herdly J, Philippe E. Acquired dental defects and salivary gland lesions after irradiation for carcinoma. J Am Dent Assoc 1965;70:868-883.

8. Elzay RP, Levitt SH, Sweeney WT. Histologic effect of fractionated doses of selectively applied megavoltage irradiation on the major salivary glands of the albino rat. Radiology 1969;93:146-152.

9. Sinn DP, Stoker NG, Epker BN. Effects of fractionated doses of cobalt 60 irradiation on rabbit submandibular glands: light microscopic studies. J Oral Surg 1972;30:277-283.

10. Savage NW, Adkins KF, Kruger BJ. The effects of fractionated megavoltage $\mathrm{X}$-irradiation on the rat submandibular gland: an assessment by light microscopy and autoradiography. Aust Dent J 1985; $30: 1-7$.

11. Savage NW, Kruger BJ, Adkins KF. Rat submandibular gland microvasculature following fraction- ated megavoltage irradiation. Aust Dent J 1985; 30:99-103.

12. Stephens LC, King GK, Peters LJ, Ang KK, Schultheiss TE, Jardine JH. Unique radiosensitivity of serous cells in rhesus monkey submandibular glands. Am J Pathol 1986;124:479-487.

13. Ahlner BH, Hagelqvist E, Lind MG, Rudén BI. Irradiation of rabbit submandibular glands. Histology and morphometry after $15 \mathrm{~Gy}$. Acta Otolaryngol 1993;113:210-219.

14. Price RE, Ang KK, Stephens LC, Peters LJ. Effects of continuous hyperfractionated accelerated and conventionally fractionated radiotherapy on the parotid and submandibular salivary glands of rhesus monkeys. Radiother Oncol 1995;34:39-46.

15. Navarro CM, Chan C, Onofre MA, Cordeiro RCL, Raveli DB. Estudo histomorfológico de glândulas submandibulares de rato submetidas a doses baixas de radiação X. Rev Odontol Unesp 1996;25:259267.

16. Friedrich RE, Bartel-Friedrich S, Holzhausen HJ, Lautenschläger $\mathrm{C}$. The effect of external fractionated irradiation on the distribution pattern of extracellular matrix proteins in submandibular salivary glands of the rat. J Craniomaxillofac Surg 2002;30: 246-254.

17. Coppes RP, Vissink A, Konings AW. Comparison of radiosensitivity of rat parotid and submandibular glands after different radiation schedules. Radiother Oncol 2002;63:321-328.

18. Radfar L, Sirois DA. Structural and functional injury in minipig salivary glands following fractionated exposure to $70 \mathrm{~Gy}$ of ionizing radiation: an animal model for human radiation-induced salivary gland injury. Oral Surg Oral Med Oral Pathol Oral Radiol Endod 2003;96:267-274.

19. Nagler RM. Effects of head and neck radiotherapy on major salivary glands - animal studies and human implications. In Vivo 2003;17:369-375.

20. Dale AC. Glândulas salivares. In: Ten Cate AR, editor. Histologia bucal. Desenvolvimento, estrutura e função. $4 \mathrm{a}-$ ed. Rio de Janeiro, RJ: Guanabara Koogan, 2001;296-322.

21. Sagowski C, Wenzel S, Jenicke L, et al. Reducing late toxicity with amifostine in fractionated irradiation of the rat salivary glands. HNO 2002;50:822828.

22. Abok K, Brunk U, Jung B, Ericsson J. Morphologic and histochemical studies on the differing radiosensitivity of ductular and acinar cells of the rat submandibular gland. Virchows Arch [B] 1984;45: 443-460.

23. Mathes SJ, Alexander J. Radiation injury. Surg Oncol Clin N Am 1996;5:809-824.

24. Cotran RS, Kumar V, Collins T. Patologia celular I: lesão e morte da célula. In: Cotran RS, Kumar V, Collins T, editors. Robbins Patologia estrutural e funcional. $6^{\underline{a}}$ ed. Rio de Janeiro, RJ: Guanabara Koogan, 2000;1-26.

25. Regezi JA, Sciubba JJ. Condições ulcerativas. In: Regezi JA, Sciubba JJ, editors. Patologia bucal: correlações clinicopatológicas. 3르 ed. Rio de Janeiro, RJ: Guanabara Koogan, 2000;27-75.

26. Junqueira LC, Carneiro J. Glândulas anexas do tubo digestivo. In: Junqueira LC, Carneiro J. Histologia básica. 9ae ed. Rio de Janeiro, RJ: Guanabara Koogan, 1999;270-286. 